\title{
Mean and Variance of Time to Recruitment in a Two Graded Manpower System with Correlated Inter-decision Times involving depletion having Independent and Non-Identically Distributed Random Variables
}

\author{
S.Jenita ${ }^{1} \&$ S.Sendhamizh Selvi ${ }^{2}$ \\ ${ }^{1}$ Research Scholar, PG \& Research Department of Mathematics, Government Arts College,Trichy-22,TN, \\ India. \\ ${ }^{2}$ Assistant Professor, PG \& Research Department of Mathematics, Government Arts College,Trichy-22,TN, \\ India.
}

\begin{abstract}
:
In this paper, an organization subjected to a random exit of personnel due to policy decisions taken by the organization is considered; there is an associated loss of manpower if a person quits the organization. As the exit of personnel is unpredictable, a recruitment policy involving two thresholds, optional and mandatory is suggested to enable the organization to plan its decision on appropriate univariate policy of recruitment. Based on shock model approach, three mathematical models are constructed using an appropriate univariate policy of recruitment. The analytical expressions for mean and variance of time to recruitment is obtained when i) the loss of manpower forms a sequence of independent and non-identically distributed exponential random variables ii) inter-decision times are exchangeable and constantly correlated exponential random variables iii) the optional and mandatory thresholds having exponential distribution.
\end{abstract}

Keywords: Manpower planning, Shock models, Univariate recruitment policy,Hypo-Exponential distribution, Exchangeable and Constantly Correlated Exponential Random Variables.

\section{INTRODUCTION}

Exodus of personnel is a common phenomenon in any marketing organization whenever the organization announces revised policies regarding scales target, revision of wages, incentives, etc. this in turn produces loss in man hours, which adversely affects the sales turnover of the organization. Frequent recruitment is not advisable as it will be expensive due to cost of recruitment. As the loss of man hours is unpredictable, a suitable recruitment policy has to be designed to overcome this loss. Esary, Marshall and Procham [7] have stated a replacement policy for a device, which is exposed to shocks. One univariate recruitment policy based on this replacement policy under shock model approach in reliability theory suggested that recruitment is done whenever the cumulative loss of man hours crosses a particular level known as threshold or breakdown point; otherwise, the organization reaches an uneconomic status. A detailed account of the application of stochastic processes in manpower planning models can be seen from Bartholomew and Morris [1], Bartholomew and Forbes [2]. The problem of finding the time to recruitment is studied for a single grade and multigrade system by several authors under different conditions. For a single graded manpower system, Sathiyamoorthy and Elangovan [17] have obtained mean and variance of time to recruitment assuming that the random variables denoting staff depletion are independent and identically distributed random variables, using cumulative damage model concept without using any cost structure. Mariappan and Srinivasan [14] have extended the result when the inter-decision times are exchangeable and constantly correlated exponential random variables for a single graded system. Sathiyamoorthy and parthasarathy [18] have obtained expected time to recruitment using univariate CUM policy of recruitment when (i) the loss of man hours is a exponential random variable (ii) the distribution of the threshold has SCBZ property (iii) the inter-decision times are independent and identically exponential random variables. Kasturri and Srinivasan [9] have extended the results of Sathiyamoorthy and parthasarathy [18] when the inter-decision times are exchangeable and constantly correlated exponential random variables. Brindha and Srinivasan [3],[4],[5],[6] have considered the problem of time to recruitment are obtained by considering a bivariate max policy of recruitment involving a constant threshold, geometric threshold, exponential threshold, a threshold whose distribution has the SCBZ property is suggested when the inter-decision times are exchangeable and constantly correlated exponential random variables. Komathi and Srinivasan [10],[11],[12],[13] have obtained the variance of time to recruitment in a single grade manpower system with correlated inter-decision times using a bivariate policy of recruitment with constant threshold ,geometric threshold using bivariate max policy with constant threshold, geometric threshold. For a two graded systems, Sathiyamoorthy and Parthasarathy [19] have obtained the mean time to recruitment under suitable conditions. Mercy Alice and Esther Clara and Srinivasan [15] have studied mean and variance of the time to recruitment using univariate recruitment policy when (i) the loss of man hours is independent and identically exponential random variables (ii) the inter-decision times are exchangeable and constantly correlated exponential random variables (iii) the thresholds are combined. 
Sendhamizhselvi [20] has discussed expected time to recruitment in manpower model for a multigraded system associated with an univariate policy of recruitment.

The objective of the present paper is to obtain mean and variance of time to recruitment when

i) the loss of manpower forms a sequence of independent and non-identically distributed continuous random variables ii) inter-decision times are exchangeable and constantly correlated exponential random variables iii) the optional and mandatory thresholds having exponential distribution.

\section{ASSUMPTIONS AND DESCRIPTION FOR MODEL-I}

1. An organization having two grades in which decisions are taken at random epochs in $(0, \infty)$ and at every decision making epoch a random number of persons quit the organization. There is an associated loss of man hours to the organization if a person quits.

2. It is assumed that the loss of man hours is linear and cumulative.

3. The loss of man hours at any decision epoch forms a sequence of independent and Non-identically distributed random variables.

4. The inter-decision times are exchangeable and constantly correlated exponential random Variables.

5. The loss of man hours and inter-decision times are statistically Independent.

6. There is an optional and mandatory thresholds for the loss of manpower in the organization.

7. The loss of manpower at any decision epoch, the optional and mandatory threshold levels are Statistically independent.

8. The optional threshold level is less than the mandatory threshold level.

\section{NOTATIONS}

$X_{i} \quad: \quad$ The loss of manhours due to the $\mathrm{i}^{\text {th }}$ decision epoch $\mathrm{i}=1,2,3 \ldots \ldots$ forming a sequence of independent and non- identically distributed exponential random variables with parameter $\alpha_{i}\left(\alpha_{i}>0\right)$.

$\mathrm{G}_{\mathrm{i}}($.$) : \quad$ The distribution function of $\mathrm{X}_{\mathrm{i}}$

$\mathrm{g}_{\mathrm{i}}($.$) \quad : \quad$ The probability density function of $\mathrm{X}_{\mathrm{i}}$ with mean $\frac{1}{\alpha_{i}}\left(\alpha_{i}>0\right)$

$\mathrm{S}_{\mathrm{k}} \quad$ : $\quad$ Cumulative loss of manpower in the first $\mathrm{k}$-decisions $(\mathrm{k}=1,2,3 \ldots)$

$$
S_{k}=\sum_{i=1}^{k} X_{i}
$$

$\mathrm{G}_{\mathrm{k}}($.$) \quad : The distribution function of sum of \mathrm{k}$ independent and non-identically distributed exponential random variables.

$\mathrm{g}_{\mathrm{k}}() \quad:$.$\quad The probability density function of \mathrm{S}_{\mathrm{k}}$

we note that $\quad \mathrm{G}_{\mathrm{k}}(\mathrm{t})=\sum_{i=1}^{k} \mathrm{c}_{\mathrm{i}}\left(1-e^{-\alpha_{i} t}\right), \mathrm{g}_{\mathrm{k}}(\mathrm{t})=\sum_{i=1}^{k} \mathrm{c}_{\mathrm{i}} \alpha_{i} e^{-\alpha_{i} t}$

$$
g_{k}^{*}(s)=\sum_{i=1}^{k} \quad \mathrm{c}_{\mathrm{i}} \frac{\alpha_{i}}{\alpha_{i}+s} \quad \text { Where } c_{i}=\prod_{j=1}^{k} \frac{\alpha_{j}}{\alpha_{j}-\alpha_{i}}, i=1,2,3 \ldots k
$$

$g_{k}^{*}():. \quad \quad$ k-fold convolution of $\mathrm{S}_{\mathrm{k}}$

$\mathrm{U}_{\mathrm{i}} \quad$ : $\quad$ The time between (i-1) and $\mathrm{i}^{\text {th }}$ decision epoch. $\mathrm{U}_{\mathrm{i}}$ 's are exchangeable and constantly correlated exponential random variables.

$\overline{F_{k}}($.$) \quad :Laplace Transform of \mathrm{F}_{\mathrm{k}}($.)

$\overline{f_{k}^{*}}() \quad:$.$\quad Laplace Transform of \mathrm{f}_{\mathrm{k}}($.

$\rho \quad$ : $\quad$ Correlation between $\mathrm{U}_{\mathrm{i}} \& \mathrm{U}_{\mathrm{j}}, \mathrm{i} \neq \mathrm{j}$

$\mathrm{u} \quad$ : $\quad$ Mean of inter-decision times

$\mathrm{u}=\frac{v}{(1-\rho)}$

$\psi(\mathrm{n}, \mathrm{x}): \quad \quad \int_{0}^{x} e^{-\epsilon} \in^{n-1} \mathrm{~d} \epsilon$

$\mathrm{m}(\mathrm{s}) \quad: \quad \frac{1}{1+v s}$

$\mathrm{Y}_{1}, \mathrm{Y}_{2}: \quad$ The continuous random variables denoting the optional thresholds levels for the grade 1 and grade 2

follows exponential distribution with parameters $\lambda_{1} \& \lambda_{2}$ respectively.

$\mathrm{Z}_{1}, \mathrm{Z}_{2}: \quad$ The continuous random variables denoting the mandatory thresholds levels for the grade 1 and grade 2

DOI: $10.9790 / 5728-1303051823 \quad$ www.iosrjournals.org $\quad 19 \mid$ Page




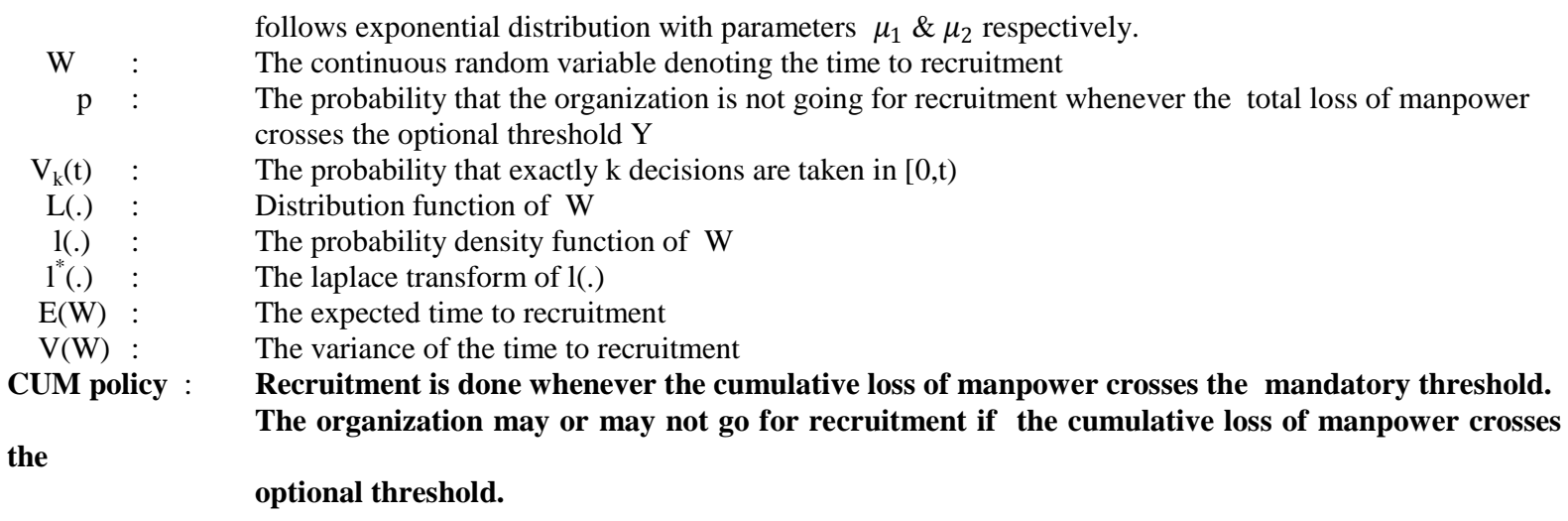

\section{MAIN RESULTS}

The survival function of $\mathrm{W}$ is given by

$\mathrm{P}(\mathrm{W}>\mathrm{t})=\sum_{k=0}^{\infty} \quad[$ Probability that exactly $\mathrm{k}$-decisions are taken in $[0, \mathrm{t}), \mathrm{k}=0,1,2, \ldots$.

[Probability that the total number of exists in these k-decisions does not cross the optional level $\mathrm{Y}$ or the total number of exists in these k-decisions crosses the optional level Y but lies below the mandatory

level Z and the organization is not making recruitment]

$\mathrm{P}(\mathrm{W}>\mathrm{t})=\sum_{k=0}^{\infty} \mathrm{V}_{\mathrm{k}}(\mathrm{t}) \mathrm{P}\left(\mathrm{S}_{\mathrm{k}}<\mathrm{Y}\right)+\sum_{k=0}^{\infty} \mathrm{V}_{\mathrm{k}}(\mathrm{t}) \mathrm{P}\left(\mathrm{S}_{\mathrm{k}} \geq \mathrm{Y}\right) \mathrm{P}\left(\mathrm{S}_{\mathrm{k}}<\mathrm{Z}\right) \mathrm{p}$

4.1 Model I

For maximum model, consider $\mathrm{P}\left(\mathrm{S}_{\mathrm{k}}<\mathrm{Y}\right)$, conditioning upon $\mathrm{S}_{\mathrm{k}}$ and using the law of total probability, we get

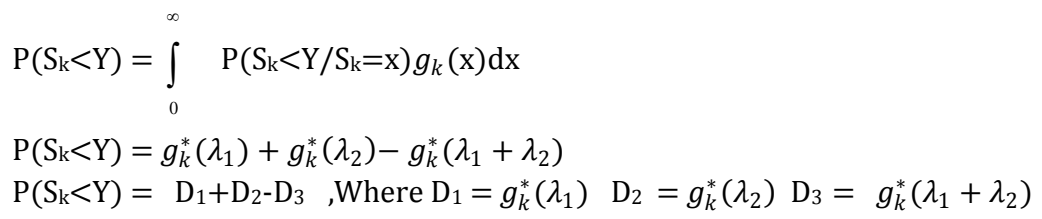

Similarly

$\mathrm{P}\left(\mathrm{S}_{\mathrm{k}}<\mathrm{Z}\right)=g_{k}^{*}\left(\mu_{1}\right)+g_{k}^{*}\left(\mu_{2}\right)-g_{k}^{*}\left(\mu_{1}+\mu_{2}\right)$

$\mathrm{P}\left(\mathrm{S}_{\mathrm{k}}<\mathrm{Z}\right)=\mathrm{D}_{4}+\mathrm{D}_{5}-\mathrm{D}_{6}$ Where $\mathrm{D}_{4}=g_{k}^{*}\left(\mu_{1}\right), \mathrm{D}_{5}=g_{k}^{*}\left(\mu_{2}\right), \mathrm{D}_{6}=g_{k}^{*}\left(\mu_{1}+\mu_{2}\right)$

Substituting (3) \& (5) in (1),we get

$$
\begin{aligned}
& \mathrm{P}(\mathrm{W}>\mathrm{t})=\sum_{\mathrm{k}=0}^{\infty} \mathrm{V}_{\mathrm{k}}(\mathrm{t})\left\{\left(\mathrm{D}_{1}+\mathrm{D}_{2}-\mathrm{D}_{3}\right)\left(1-\mathrm{p}\left(\mathrm{D}_{4}+\mathrm{D}_{5}-\mathrm{D}_{6}\right)+\mathrm{p}\left(\mathrm{D}_{4}+\mathrm{D}_{5}-\mathrm{D}_{6}\right)\right\}\right. \\
& \mathrm{P}(\mathrm{W}>\mathrm{t})=\sum_{\mathrm{k}=0}^{\infty} \mathrm{V}_{\mathrm{k}}(\mathrm{t})\left\{\mathrm{B}_{\mathrm{k}}\left(1-\mathrm{p} \mathrm{C}_{\mathrm{k}}\right)+\mathrm{p} \mathrm{C}_{\mathrm{k}}\right\} \\
& \text { Where } \mathrm{B}_{\mathrm{k}}=\mathrm{D}_{1}+\mathrm{D}_{2}-\mathrm{D}_{3}, \mathrm{C}_{\mathrm{k}}=\mathrm{D}_{4}+\mathrm{D}_{5}-\mathrm{D}_{6} \\
& \mathrm{P}(\mathrm{W}>\mathrm{t})=\sum_{\mathrm{k}=0}^{\infty} \mathrm{V}_{\mathrm{k}}(\mathrm{t}) \mathrm{A}_{\mathrm{k}}, \text { where } A_{k}=\mathrm{B}_{\mathrm{k}}\left(1-\mathrm{p} \mathrm{C}_{\mathrm{k}}\right)+\mathrm{p} \mathrm{C}_{\mathrm{k}}
\end{aligned}
$$

From renewal theory (Medhi),

$$
\mathrm{V}_{\mathrm{k}}(\mathrm{t})=\mathrm{F}_{\mathrm{k}}(\mathrm{t})-\mathrm{F}_{\mathrm{k}+1}(\mathrm{t}) \text { with } \mathrm{F}_{0}(\mathrm{t})=1
$$

Since $\mathrm{L}(\mathrm{t})=1-\mathrm{P}(\mathrm{W}>\mathrm{t})$ and $\mathrm{l}(\mathrm{t})=\frac{d}{d t} \mathrm{~L}(\mathrm{t}), \mathrm{l}^{*}(\mathrm{~s})=$ Laplace Transform of $\mathrm{l}(\mathrm{t})$, we get

$$
\mathrm{l}^{*}(\mathrm{~s})=\sum_{k=0}^{\infty} f_{k+1}^{*}(\mathrm{~s}) \mathrm{A}_{\mathrm{k}}-\sum_{k=0}^{\infty} f_{k}^{*}(\mathrm{~s}) \mathrm{A}_{\mathrm{k}}
$$

By assumption, $\left\{\mathrm{U}_{\mathrm{i}}\right\}$ is a sequence of exchangeable and constantly correlated random variables each following the exponential distribution with probability density function is 


$$
\mathrm{f}(\mathrm{x})=\left(\frac{1}{u}\right) e^{-\left(\frac{x}{u}\right)}, \mathrm{u}>0,0<\mathrm{x}<\infty
$$

As in Gurland (1955), we get the characteristic function of $\left\{U_{i}\right\}$ as

$$
\psi\left(\gamma_{1}, \gamma_{2}, \gamma_{3}, \ldots . \gamma_{k}\right)=\left|\begin{array}{cccc}
1-i \gamma_{1} a R & -1 i \gamma_{1} a R & \ldots & -i \gamma_{1} a R \\
-i \gamma_{2} a R & 1-i \gamma_{2} a R & \ldots & -i \gamma_{2} a R \\
\ldots & \ldots & \ldots & \ldots \\
-i \gamma_{k} a R & -i \gamma_{k} a R & \ldots & 1-i \gamma_{k} a R
\end{array}\right|^{-1}
$$

And the cumulative distribution function of $\sum_{i=1}^{k} \mathrm{U}_{\mathrm{i}}$ as

$$
F_{k}(\mathrm{t})=\frac{1-\rho}{1-\rho+k \rho} \sum_{i=0}^{k}\left(\frac{k \rho}{1-\rho+k \rho}\right)^{i} \frac{\psi(k+i, x / v)}{(k+i-1) !}
$$

Where $\rho$ is a constant correlation between $\mathrm{U}_{\mathrm{i}}$ and $\mathrm{U}_{\mathrm{j}}, \mathrm{i} \neq \mathrm{j}$

$$
\psi(k+i, x / v)=\int_{0}^{x / v} e^{-z} z^{k+i-1} \mathrm{dz}, \text { where } \mathrm{v}=\lambda(1-\rho)
$$

Using (9) in (8), we get

$$
\begin{aligned}
& F_{k}(\mathrm{t})=\frac{1-\rho}{1-\rho+k \rho} \sum_{i=0}^{k} \quad\left(\frac{k \rho}{1-\rho+k \rho}\right)^{i} \frac{1}{(k+i-1) !} \int_{0}^{x / v} e^{-z} z^{k+i-1} \mathrm{dz} \\
& F_{k}(\mathrm{t})=\frac{1-\rho}{1-\rho+k \rho} \sum_{i=0}^{\infty}\left(\frac{k \rho}{1-\rho+k \rho}\right)^{i}\left[1-\sum_{j=0}^{k+i-1} \frac{e^{-x / v}(x / v)^{k+i-j-1}}{(k+i-j-1) !}\right]
\end{aligned}
$$

Taking Laplace Stieltje's Transform ,the equation (11) becomes

$\overline{F_{k}}(\mathrm{~s})=\mathrm{s} \int_{0}^{\infty} e^{-s t}\left\{\frac{1-\rho}{1-\rho+k \rho} \sum_{i=0}^{\infty}\left(\frac{k \rho}{1-\rho+k \rho}\right)^{i}\left[1-\sum_{j=0}^{k+i-1} \frac{e^{-t / v}(t / v)^{k+i-j-1}}{(k+i-j-1) !}\right]\right\} \mathrm{dt}$

$\overline{F_{k}}(\mathrm{~s})=\frac{(1-\rho)(1+v s)^{1-k}}{(1+v s)(1-\rho)+v s k \rho}$, where $\mathrm{v}=\lambda(1-\rho)$

Similarly

$$
\begin{aligned}
& \overline{F_{k+1}}(\mathrm{~s})=\frac{(1-\rho)(1+v s)^{-k}}{(1+v s)(1-\rho)+v s(k+1) \rho} \\
& {\left[\frac{d}{d s} \overline{F_{k}}(\mathrm{~s})\right]_{\mathrm{s}=0}=-\mathrm{ku} \text {, where } \mathrm{u}=\frac{v}{1-\rho}} \\
& {\left[\frac{d}{d s} \overline{F_{k+1}}(\mathrm{~s})\right]_{\mathrm{s}=0}=-\mathrm{u}(\mathrm{k}+1), \text { where } \mathrm{u}=\frac{v}{1-\rho}} \\
& {\left[\frac{d^{2}}{d^{2}} \overline{F_{k}}(\mathrm{~s})\right]_{\mathrm{s}=0}=u^{2}\left[\rho^{2} k(k-1)+k(k+1)\right]} \\
& {\left[\frac{d^{2}}{d^{2}} \overline{F_{k+1}}(\mathrm{~s})\right]_{\mathrm{s}=0}=u^{2}\left\{\rho^{2}(k+1) k+(k+1)(k+2)\right\}}
\end{aligned}
$$

We note that

$$
\begin{aligned}
& \mathrm{E}(\mathrm{W})=-\left[\frac{d}{d s} \mathrm{I}^{*}(\mathrm{~s})\right]_{s=0} \\
& \mathrm{E}\left(\mathrm{W}^{2}\right)=\left[\frac{d^{2}}{d s^{2}} \mathrm{l}^{*}(\mathrm{~s})\right]_{s=0} \\
& \mathrm{~V}(\mathrm{~W})=\mathrm{E}\left(\mathrm{W}^{2}\right)-(E(W))^{2}
\end{aligned}
$$

Using the equation (7),(14) and (15) in (19),we get

$$
\begin{aligned}
{\left[\frac{d}{d s} \mathrm{l}^{*}(\mathrm{~s})\right] \mathrm{s}=0 } & =\sum_{k=0}^{\infty}[-\mathrm{u}] A_{k} \\
\mathrm{E}(\mathrm{W}) & =-\left[\frac{d}{d s} \mathrm{l} *(\mathrm{~s})\right] \mathrm{s}=0 \\
\mathrm{E}(\mathrm{W}) & =\mathrm{u} \sum_{k=0}^{\infty} A_{k}
\end{aligned}
$$

$\mathrm{E}(\mathrm{W})=\frac{v}{1-\rho} \sum_{k=0}^{\infty} A_{k}$, where $\mathrm{u}=\frac{v}{1-\rho}$

Equation (21) gives mean time to recruitment for model I

Using the equations (7), (16) \& (17) in (19), we get 
$\mathrm{E}\left(\mathrm{W}^{2}\right)=2\left(\frac{v}{1-\rho}\right)^{2} \sum_{k=0}^{\infty}\left[\rho^{2} k+k+1\right] A_{k}$

Using $\mathrm{V}(\mathrm{W})=\mathrm{E}\left(\mathrm{W}^{2}\right)-(E(W))^{2}$

we get the variance of time to recruitment for model I.

Where $A_{k}=\left[g_{k}^{*}\left(\lambda_{1}\right)+g_{k}^{*}\left(\lambda_{2}\right)-g_{k}^{*}\left(\lambda_{1}+\lambda_{2}\right)\left[1-p\left(g_{k}^{*}\left(\mu_{1}\right)+g_{k}^{*}\left(\mu_{2}\right)-g_{k}^{*}\left(\mu_{1}+\mu_{2}\right)\right)\right]\right.$

$+\mathrm{p}\left[g_{k}^{*}\left(\mu_{1}\right)+g_{k}^{*}\left(\mu_{2}\right)-g_{k}^{*}\left(\mu_{1}+\mu_{2}\right)\right]$

\subsection{Model II :}

For minimum model, the optional and mandatory thresholds for the organization are given by

$\mathrm{Y}=\min \left(\mathrm{Y}_{1}, \mathrm{Y}_{2}\right) \& \mathrm{Z}=\min \left(\mathrm{Z}_{1}, \mathrm{Z}_{2}\right)$.

$\mathrm{P}\left(\mathrm{S}_{\mathrm{k}}<\mathrm{Y}\right)=g_{k}^{*}\left(\lambda_{1}+\lambda_{2}\right)$

$\mathrm{P}\left(\mathrm{S}_{\mathrm{k}}<\mathrm{Y}\right)=\mathrm{D}_{3}$, Where $\mathrm{D}_{3}=g_{k}^{*}\left(\lambda_{1}+\lambda_{2}\right)$

Similarly

$\mathrm{P}\left(\mathrm{S}_{\mathrm{k}}<\mathrm{Z}\right)=g_{k}^{*}\left(\mu_{1}+\mu_{2}\right)$

$\mathrm{P}\left(S_{k}<\mathrm{Z}\right)=D_{6}$, where $\quad D_{6}=g_{k}^{*}\left(\mu_{1}+\mu_{2}\right)$

$\mathrm{P}(\mathrm{W}>\mathrm{t}) \quad=\sum_{\mathrm{k}=0}^{\infty} \mathrm{V}_{\mathrm{k}}(\mathrm{t})\left\{\mathrm{D}_{3}\left(1-\mathrm{pD}_{6}\right)+\mathrm{pD}_{6}\right\}$

$\mathrm{P}(\mathrm{W}>\mathrm{t})=\sum_{\mathrm{k}=0}^{\infty} \mathrm{V}_{\mathrm{k}}(\mathrm{t}) \mathrm{A}_{\mathrm{k}}$, where $\mathrm{A}_{\mathrm{k}}=\mathrm{B}_{\mathrm{k}}\left(1-\mathrm{p} \mathrm{C}_{\mathrm{k}}\right)+\mathrm{p} \mathrm{C}_{\mathrm{k}}$

The results of $\mathrm{E}(\mathrm{W})$ and $\mathrm{V}(\mathrm{W})$ of model II is the same results as in model $\mathrm{I}$, but

Where $A_{k}=g_{k}^{*}\left(\lambda_{1}+\lambda_{2}\right)\left[1-\mathrm{p} g_{k}^{*}\left(\mu_{1}+\mu_{2}\right)\right]+p g_{k}^{*}\left(\mu_{1}+\mu_{2}\right)$

4.3 Model III

For combined model, the optional \& mandatory threshold for the organization are given by

$\mathrm{Y}=\mathrm{Y}_{1}+\mathrm{Y}_{2} \& \mathrm{Z}=\mathrm{Z}_{1}+\mathrm{Z}_{2}$.

$\mathrm{P}\left(\mathrm{S}_{\mathrm{k}}<\mathrm{Y}\right)=\frac{\lambda_{1}}{\lambda_{1}-\lambda_{2}} g_{k}^{*}\left(\lambda_{2}\right)-\frac{\lambda_{2}}{\lambda_{1}-\lambda_{2}} g_{k}^{*}\left(\lambda_{1}\right)$

$\mathrm{P}\left(\mathrm{S}_{\mathrm{k}}<\mathrm{Y}\right)=\mathrm{C}_{1} \mathrm{D}_{2}-\mathrm{C}_{2} \mathrm{D}_{1}$

Where $\mathrm{C}_{1}=\frac{\lambda_{1}}{\lambda_{1}-\lambda_{2}}, \mathrm{C}_{2}=\frac{\lambda_{2}}{\lambda_{1}-\lambda_{2}}, \mathrm{D}_{1}=g_{k}^{*}\left(\lambda_{1}\right), \mathrm{D}_{2}=g_{k}^{*}\left(\lambda_{2}\right)$

Similarly

$\mathrm{P}\left(\mathrm{S}_{\mathrm{k}}<\mathrm{Z}\right)=\frac{\mu_{1}}{\mu_{1}-\mu_{2}} g_{k}^{*}\left(\mu_{2}\right)-\frac{\mu_{2}}{\mu_{1}-\mu_{2}} g_{k}^{*}\left(\mu_{1}\right)$

$\mathrm{P}\left(\mathrm{S}_{\mathrm{k}}<\mathrm{Z}\right)=\mathrm{C}_{3} \mathrm{D}_{5}-\mathrm{C}_{4} \mathrm{D}_{4}$

Where $\mathrm{C}_{3}=\frac{\mu_{1}}{\mu_{1}-\mu_{2}}, \mathrm{C}_{4}=\frac{\mu_{2}}{\mu_{1}-\mu_{2}}, \mathrm{D}_{4}=g_{k}^{*}\left(\mu_{1}\right), \mathrm{D}_{5}=g_{k}^{*}\left(\mu_{2}\right)$

$\mathrm{P}(\mathrm{W}>\mathrm{t})=\sum_{\mathrm{k}=0}^{\infty} \mathrm{V}_{\mathrm{k}}(\mathrm{t})\left\{\left(\mathrm{C}_{1} \mathrm{D}_{2}-\mathrm{C}_{2} \mathrm{D}_{1}\right)\left(1-\mathrm{p}\left(\mathrm{C}_{3} \mathrm{D}_{5}-\mathrm{C}_{4} \mathrm{D}_{4}\right)\right)+\mathrm{p}\left(\mathrm{C}_{3} \mathrm{D}_{5}-\mathrm{C}_{4} \mathrm{D}_{4}\right)\right\}$

$\mathrm{P}(\mathrm{W}>\mathrm{t})=\sum_{\mathrm{k}=0}^{\infty} \mathrm{V}_{\mathrm{k}}(\mathrm{t}) \mathrm{A}_{\mathrm{k}}$, where $\mathrm{A}_{\mathrm{k}}=\mathrm{B}_{\mathrm{k}}\left(1-\mathrm{p} \mathrm{C}_{\mathrm{k}}\right)+\mathrm{p} \mathrm{C}_{\mathrm{k}}$

The results of $\mathrm{E}(\mathrm{W})$ and $\mathrm{V}(\mathrm{W})$ of model III is the same results as in model I, but

$$
\text { Where } \begin{aligned}
A_{\mathrm{k}}= & {\left[\frac{\lambda_{1}}{\lambda_{1}-\lambda_{2}} g_{k}^{*}\left(\lambda_{2}\right)-\frac{\lambda_{2}}{\lambda_{1}-\lambda_{2}} g_{k}^{*}\left(\lambda_{1}\right)\right]\left[1-p\left(\frac{\mu_{1}}{\mu_{1}-\mu_{2}} g_{k}^{*}\left(\mu_{2}\right)-\frac{\mu_{2}}{\mu_{1}-\mu_{2}} g_{k}^{*}\left(\mu_{1}\right)\right)\right] } \\
& +\mathrm{p}\left[\left(\frac{\mu_{1}}{\mu_{1}-\mu_{2}} g_{k}^{*}\left(\mu_{2}\right)-\frac{\mu_{2}}{\mu_{1}-\mu_{2}} g_{k}^{*}\left(\mu_{1}\right)\right)\right]
\end{aligned}
$$

V.

Conclusion

The manpower planning model developed in this paper more general compare to earlier work in this direction and it can be used to plan for the adequate provision of manpower for the organization at graduate, professional and management level in the context of attrition. There is a scope for studying the applicability of the designed model using simulation. Further, by collecting relevant data, one can test the goodness of fit for the distributions assumed in this paper. The findings given in this paper enable one to estimate manpower gap in future, thereby facilitating the assessment of manpower profile in predicting future manpower development not only on industry but also in a wider domain. The present work can be studied for a two grade manpower system. This work also can be extended in two sources of depletion for two graded manpower system.

\section{References}

[1] Barthlomew.D.J. and Morris.B.R..1971.Aspects of Manpower Planning, Elsevier Publishing Company. New York.

[2] Barthlomew.D.J and Forbes.A.F., Statistical Technique for Manpower Planning, John Wiley and Sons(1979). 
[3] Brindha.M \&Srinivasan.A.,Stochastic Model on the Time for Recruitment in a Single Graded Manpower System Associated with a Bivariate Policy

of Recruitment I, Acta Ciencia Indica(2008),Vol XXXIVM,No.4,pp (1959-1963).

[4] Brindha.M \&Srinivasan.A.,Stochastic Model on the Time for Recruitment in a Single Graded Manpower System Associated with a Bivariate Policy of Recruitment II, Acta Ciencia Indica(2008),Vol XXXIVM,No.4,pp (2005-2009).

[5] Brindha.M \&Srinivasan.A.,Stochastic Model on the Time for Recruitment in a Single Graded Manpower System Associated with a Bivariate Policy

of Recruitment III, Acta Ciencia Indica(2008),Vol XXXIVM,No.4,pp (2103-2106).

[6] Brindha.M \&Srinivasan.A.,Stochastic Model on the Time for Recruitment in a Single Graded Manpower System Associated with a Bivariate Policy

of Recruitment IV, Acta Ciencia Indica(2008), Vol XXXIVM,No.4,pp (2131-2134).

[7] Esary.J.D., Marshall.A.W. and Prochan.,1973,Ann.Probability,1(4),pp.627-649.

[8] Karlin, Samuel and Taylor M.Hayward., A First Course in Stochastic Process, Academic Press, Newyork, San Francisco, London(1981).

[9] Kasturri.K and Srinivasan.S., Expected Time for Recruitment Correlated Inter- Decision Times of Exits when Threshold Distribution has SCBZ

Property, Acta Ciencia Indica(2005),Vol XXXIM,No.1,pp(276-283).

[10] Komathi.S and Srinivasan.A., Variance of the Time to Recruitment in a Single Grade Manpower System with Correlated InterDecision Times

Using a Bivariate Policy of Recruitment I, Acta Ciencia Indica(2008), Vol XXXIVM, No.4,pp (1901- 1904).

[11] Komathi.S and Srinivasan.A., Variance of the Time to Recruitment in a Single Grade Manpower System with Correlated InterDecision Times Using a Bivariate Policy of Recruitment II, Acta Ciencia Indica(2008),Vol XXXIVM,No.4, pp (1855 1859).

[12] Komathi.S and Srinivasan.A., Variance of the Time to Recruitment in a Single Grade Manpower System with Correlated InterDecision Times Using

a Bivariate Policy of Recruitment IV, Acta Ciencia Indica(2008),Vol XXXIVM,No.4, pp (2091-2094).

[13] Komathi.S and Srinivasan.A., Variance of the Time to Recruitment in a Single Grade Manpower System with Correlated InterDecision Times Using a Bivariate Policy of Recruitment V, Acta Ciencia Indica(2008), Vol XXXIVM,No.4, pp (20612064).

[14] Mariappan.P and Srinivasan.S.,Expected Time to Recruitment in Manpower Planning Associated with Correlated Renewal Secquences-A Shock Model Approach, Acta Ciencia Indica(2001a),Vol XXXVIIM,No.3,pp(351-356).

[15] Mercy Alice.B and Esther Clara.J.B and Srinivasan.A.,Mean and Variance of the Time to Recruitment in a Two Graded Manpower System with Correlated Inter- Decision Times, Acta Ciencia Indica(2011),Vol XXXVIIM,No.3,pp(583587).

[16] Rao.B.R and Talwalkers.S.,Setting the Clock Back to Zero Property of a Class of the Life Distribution, The Journal of Statistical Planning and Inference(1990),24, pp(347-352).

[17] Sathiyamoorthy.R and Elangovan.R .,Shock Model Approach to Determine the Expected Time for Recruitment, Journal of Decision and

Mathematika Science(1998),India,3,1-3,pp(67-78).

[18] Sathiyamoorthy.R and Parthasarathy.S.,On the Expected Time to Recruitment when the Threshold Distribution has SCBZ Property,International Journal of Management and Systems(2003), 19,pp(233-240).

[19] Sathiyamoorthy.R and Parthasarathy.S.,On the Expected Time to Recruitment in a Two Grade Marketing Organization, Indian Association for Productivity Quality and Reliability(2002),India,27,1,pp(77-81).

[20] Sendhamizhselvi.S.,A Study on Expected Time to Recruitment in Manpower Model for a Multigraded System Associated with an Univariate Policy of Recruitment,Ph.D Thesis, Bharathidasan University, Jan(2009).

[21] Venkat Lakshmi \& Srinivasan.A., Mean and Variance of Time to Recruitment in a Single Grade Manpower System Associated with a Bivariate Policy of Recruitment Involving an Exponential Thresholds, Journal of Mathematical Science(2007).

S. Jenita. "Mean and Variance of Time to Recruitment in A Two Graded Manpower System with Correlated Inter-Decision Times Involving Depletion Having Independent and Non-Identically Distributed Random Variables." IOSR Journal of Mathematics (IOSR-JM) 13.3 (2017): 18-23. 